\title{
Care of schizophrenia in general practice
}

\author{
Irwin Nazareth, Michael King, Andrew Haines, Sharon See Tai, Gillian Hall
}

Department of Primary

Health Care, University

College London Medical

School, Whittington

Hospital, London

N19 5NF

Irwin Nazareth, lecturer

Andrew Haines, professor

Sharon See Tai, research

analyst

Academic Department of

Psychiatry, Royal Free

Hospital Medical School,

London NW3 2QG

Michael King, senior lecturer

London SW19 7AP

Gillian Hall,

pharmacoepidemiologist

Correspondence to:

Dr Nazareth.

$B M F$ 1993;307:910
Little is known about the management of schizophrenia in general practice. ${ }^{1}$ Our aim was to compare the care of patients with schizophrenia with that of patients with chronic physical diseases and patients randomly selected from the practice register.

\section{Patients, methods, and results}

Thirteen of the 16 London general practices fulfilling required validation standards of the VAMP (value added medical products) computer research bank between April and September 1990 participated. ${ }^{2}$ A search of the computerised records identified 212 patients with a diagnosis of schizophrenia; $90 \%$ of a one in two random sample were given a lifetime diagnosis of schizophrenia according to broad diagnostic criteria. ${ }^{2}$ Each was age matched (within a five year band) and sex matched with two patients in the same practice. The first was randomly selected from a pool of patients with chronic physical diseases (epilepsy, diabetes, rheumatoid arthritis, and multiple sclerosis) and in the second from the practice register.

Information for the preceding four years was collected from the practice records. All consultations were counted and coded as physical or mental according to the presenting complaints; the number of disease specific assessments for patients with schizophrenia and chronic physical diseases was recorded. Entries in the notes pertaining to housing, employment, finances, or social outlets were counted and classed as social entries for all three groups of patients. The number of letters from hospital consultants was recorded. Prescriptions issued by the surgery without direct patient contact were classed as repeat prescriptions

Variables examined in the analysis were divided around the median of the respective control group's observations. Disease specific assessments and letters from hospital consultants were not relevant for the controls selected from the practice register. As these controls had few psychiatric consultations and repeat prescriptions binary variables were created corresponding to none or at least one such event. These variables were then analysed by conditional logistic regression for matched case-control studies with the EGRET statistical package. The aim of the regression was to determine factors predicting membership of the schizophrenia group (table).

Mental health consultations strongly predicted that a patient belonged to the schizophrenia group. Social entries were also associated with this group. Physical consultations were more strongly associated with being in the physical disease group, as were repeat prescriptions and disease specific assessments. The total consultation rate was not a significant predictor of membership of the schizophrenia group in the comparison with the physical disease group, but in the comparison with the other control group, frequent consultations (above the median of this control group) indicated that patients were 11 times more likely to belong to the schizophrenia group.

\section{Comment}

Patients with schizophrenia consulted their general practitioner more often than the average patient but with similar frequency to patients with chronic physical disorders. Mental health consultations in the two comparison groups were infrequent. Our findings confirm that patients with schizophrenia consult more often with physical complaints than the average patient, which may divert doctors from reviewing important mental health issues. ${ }^{4}$ The index disorder was more often assessed in patients with chronic physical diseases than in those with schizophrenia, who therefore received little specific management.

Results of controlled comparisons by conditional logistic regression between patients with schizophrenia and two groups of control patients

\begin{tabular}{|c|c|c|}
\hline Factor (independent variable) ${ }^{\star}$ & $\begin{array}{l}\text { Schizophrenia } \\
\text { group } v \text { chronic } \\
\text { physical disease } \\
\text { group }\end{array}$ & $\begin{array}{l}\text { Schizophrenia } \\
\text { group } v \text { control } \\
\text { group }\end{array}$ \\
\hline \multicolumn{3}{|l|}{ Consultation rate: } \\
\hline \multicolumn{3}{|l|}{ Total: } \\
\hline Odds ratio & $1 \cdot 25$ & $11 \cdot 13$ \\
\hline $\begin{array}{l}95 \% \text { Confidence interval } \\
\text { p Value }\end{array}$ & 0.81 to 1.94 & 5.4 to 22.93 \\
\hline $\begin{array}{l}\text { p Value } \\
\text { Physical: }\end{array}$ & 0.32 & $<0.001$ \\
\hline \multicolumn{3}{|l|}{ Physical: } \\
\hline Odds ratio & 0.28 & 1.9 \\
\hline $95 \%$ Confidence interval & 0.17 to 0.47 & 1.22 to 2.96 \\
\hline $\mathrm{p}$ Value & $<0.001$ & 0.004 \\
\hline \multicolumn{3}{|l|}{ Mental: } \\
\hline Odds ratio & 7.57 & 21.83 \\
\hline $95 \%$ Confidence interval & $4 \cdot 34$ to $13 \cdot 22$ & 9.63 to 49.49 \\
\hline p Value & $<0.001$ & $<0.001$ \\
\hline \multicolumn{3}{|l|}{ Social entries in notes: } \\
\hline Odds ratio & $2 \cdot 29$ & \\
\hline $95 \%$ Confidence interval & 1.37 to 3.82 & \\
\hline p Value & 0.002 & \\
\hline \multicolumn{3}{|l|}{ Repeat prescriptions issued: } \\
\hline Odds ratio & 0.54 & $2 \cdot 75$ \\
\hline $95 \%$ Confidence interval & 0.34 to 0.84 & 1.22 to 6.18 \\
\hline p Value & 0.007 & 0.014 \\
\hline \multicolumn{3}{|c|}{ Disease specific assessments undertaken: } \\
\hline Odds ratio & 0.52 & \\
\hline $95 \%$ Confidence interval & 0.34 to 0.78 & \\
\hline p Value & $<0.002$ & \\
\hline \multicolumn{3}{|l|}{ Letters from consultants received: } \\
\hline Odds ratio & 1.37 & \\
\hline $95 \%$ Confidence interval & 0.93 to 2.03 & \\
\hline p Value & $0 \cdot 17$ & \\
\hline
\end{tabular}

*Divided around median of control group.

Our study has limitations. Not all consultations are recorded, and communications with other professionals may be spoken rather than written. ${ }^{5}$ The case-control comparison, however, would have reduced the effect of such a systematic error. These results lack qualitative detail; we will be presenting data on the views of patients and their doctors elsewhere.

Patients with schizophrenia and chronic physical diseases generate a similar workload in general practice. However, a more structured approach to the care of schizophrenia is needed, with regular physical and mental state assessments and monitoring of drug treatment and closer cooperation with local psychiatric services.

'This study was funded by the Sir Jules Thorn Charitable Trust. We thank the VAMP Research Unit and the doctors, staff, and patients of the participating practices for making the study possible.

1 Nazareth I, King M. Controlled evaluation of management of schizophrenia in one general practice: a pilot study. Fam Pract 1992;9:171-2.

2 Nazareth I, King M, Haines A, Rangel L, Myers S. Accuracy of diagnosis of psychosis on a general practice computer system. $B M \mathcal{F} 1993 ; 307: 32-4$.

3 Breslow NE, Day NE. Statistical methods in cancer research Vol 1. The analysis of case control studies. Lyons: International Agency for Research on Cancer, 1980.

4 Brugha TS, Wing JK, Smith DL. Physical health of long term mentally ill in the community. Is there an unmet need? Br f Psychiatry 1989;155:777-81.

5 Pullen I, King MB. Communications between general practitioners and psychiatrists. In: Gray DP, Wright A, Pullen I, Wilkinson G, eds. Psychiatry in general practice. London: Gaskell (in press).

(Accepted 7 fuly 1993) 